International Journal of Linguistics, Literature and Translation

ISSN: 2617-0299 (Online); ISSN: 2708-0099 (Print)

DOI: $10.32996 / \mathrm{ijllt}$

Journal Homepage: www.al-kindipublisher.com/index.php/ijltt

IJLLT

\title{
Viewing Orwellian Newspeak from the Angle of Linguistics: An “Economic" Redundancy
}

\author{
Liang Liqiao \\ Postgraduate student of Graduate Institute of Interpretation and Translation (GIIT), Shanghai International Studies University, \\ Shanghai, China \\ $\square$ Corresponding Author: Liang Liqiao, E-mail: 68560948@qq.com
}

\section{ARTICLE INFORMATION ABSTRACT}

Received: 10 October 2021

Accepted: 18 November 2021

Published: 23 December 2021

DOI: $10.32996 /$ ijllt.2021.4.12.16

\section{KEYWORDS}

Linguistics; "Orwellian"; Nineteen Eighty-Four; Newspeak; Standard English; Language simplification movement
Orwell's Nineteen Eighty-Four has been widely studied, but not one of his important inventions in that novel. That is his Newspeak. From the perspective of linguistics, one of the most important characteristics of the development of language(s) is the feature of the economy, which means that language evolves in various ways to streamline and make it easier for its users to express themselves. This is not the case with the English variant "Newspeak" created by George Orwell in Nineteen Eighty-Four, which is somehow simpler in form than standard English, which was named "Oldspeak", but "Newspeak" is actually in a sense simpler than "Oldspeak". Newspeak" is actually much more obscure than "Old speech" in a sense. The reason for this may be found in comparison with several typical language simplification movements. In order to investigate the issues, former researchers` findings would be referenced, and textual evidence would be found and discussed in the article.

\section{Introduction}

The development of language is generally in line with the principle of economy. The principle of the economy has led to the development of a language that generally pursues the goal of "simplicity and conciseness" from the perspective of the speaker and the listener, respectively (Gan \& Wang, 2004). In George Orwell's 1984 appeared a "highly simplified" variant of English called "Newspeak". "Newspeak is the new official language of Oceania in which the main character Winston Smith lives, and from the original text, Newspeak should have a considerable place in the book, because the author goes out of his way to introduce it in a chapter (an appendix), and begins with the statement declaring that Newspeak is "the official language of Oceania (Orwell, 1949:278). However, this so-called "official language" does not appear much in the text of the book, and it does not seem to replace the standard English called "Old" for almost a century in the book. "As a linguistic variant developed from a strong language (i.e. English) with a wide audience base (Guo, 2002), it is theoretically unlikely that the lack of an audience would have caused the slow spread of the language, and the reason for this slow development is most likely the obscurity of the language variant itself.

Therefore, a hypothesis is proposed: Newspeak as a (fictitious) variant of English has certain concise features in the language form, but in fact, it is more obscure than standard English, which leads to the low and slow popularity in Oceania. George Orwell, as the designer of "Newspeak", designed this virtual language variant in such a way that he must have wanted to convey his concern for the human mind and its intuitive vehicle, language, through certain features of "Newspeak".

In order to prove this hypothesis, it is necessary to start with the studies of 1984 and the concept of "Newspeak" created by Orwell in the book, both at home and abroad, and to compare it with the real language simplification movement such as "Plain English", in order to reveal the problem in terms of the language itself as well as historical, political, and ideological aspects. The study of language itself and historical, political, and ideological aspects reveals the answers to these questions.

\section{Literature Review}

In this section, basic definitions and current status of domestic and international research will be introduced:

Copyright: (c) 2021 the Author(s). This article is an open access article distributed under the terms and conditions of the Creative Commons Attribution (CC-BY) 4.0 license (https://creativecommons.org/licenses/by/4.0/). Published by Al-Kindi Centre for Research and Development, London, United Kingdom. 


\subsection{The Overall Research Status of George Orwell's Nineteen Eighty-Four}

Until October 4, 2021, typing "1984 Orwell" on www.cnki.net would lead to you 180 results. On the Web of Science, input the same two keywords "1984 Orwell" will provide you with 77 results. These works can be traced back to as early as 1983 and as late as this year (2021).

Chinese researchers interested in Nineteen Eighty-Four usually examine it in terms of a specific literary or philosophical theory, examining the work itself, a specific character or phenomenon. In other words, they would take Nineteen Eight-Four purely as a literary work under most circumstances. Sometimes, such studies are conducted by comparing it with similar literary works, such as Haruki Murakami's 1 Q84 (Cao, 2018; Peng, 2015; Bi, 2015), Animal Farm, which is also Orwell's work, or Beautiful New World and We, which are also called "anti-utopia trilogy" (Zhang, 2021; Zhang, 2018). Through comparative studies, we can criticize totalitarianism, call for social ethics, and praise Orwell's "life for work", his love for democracy and freedom, and his compassion for working people(Nie, 2016). In addition, Nineteen Eight-Four also appears as an important part of the dissertation, which is mostly an analysis of the writer's writing style, a comparative study of the ideas contained in similar works of a certain era, etc.

Outside China, scholars seldom took Nineteen Eighty-Four as an isolated research subject. Rather, they take Nineteen Eighty-Four one research sources of them or use part of its content and characters as tools examining some real events as well as personnel in the material of recent five years (2017-2021). When doing research, Foreign scholars like to study (a) certain image(s) in the book, such as "the Ministry of Truth" (Karel, 2019), "desire of rebellion", and so on. In addition, some scholars also use the concepts in the works to study real political events or figures, such as the analysis of the withdrawal of the United States from UNESCO in 2018 (Lonrenzo, 2019) and even compare former U.S. President Donald Trump with "Big Brother" (Rodden, 2020). An important fact which is worth attention is that, in addition to the works of traditional English-speaking scholars, a large part of foreign works on Nineteen Eighty-Four was contributed by Russian and Korean authors, respectively. Russia, formerly the world's first socialist state, the Soviet Union, has generally been the target of Orwell's insinuations and criticisms. However, Russian scholars argue that the description of the "British Socialist Party" in 1984 bears no resemblance to the Soviet government under Stalin, but rather to the British Labour Party, which was undergoing reforms shortly after the end of World War II, so Orwell actually used the criticism of the Soviet Union to satirize the British political parties of the time (Вахитов \& Vakhitov, 2021). Newspeak is sometimes studied as part of the novel's theme, and some scholars argue that they are a satire of the bland, clichéd, and flashy texts of the governments of the time in various official documents.

To sum up, the common denominator of domestic and international studies is that the studies of Nineteen Eighty-Four are not confined to the text but combine historical context, historical evidence, textual analysis and imagery portrayal to express the criticism of totalitarianism, the pursuit of freedom and democracy, and the loud cry for the protection of man's languages and words, in other words, powerful weapons against the dictators.

\subsection{The Concept of Newspeak}

Newspeak is a language (English) variation, in other words, a linguistic concept created by Orwell in Nineteen Eighty-Four. It is derived from Standard English. In the work's appendix, "The Principles of Newspeak", the author states straightforwardly that the creation of new speech is to "reduce language and its expressions to a skeleton" so as to avoid "the possibility of thoughtcrimes emerge among Oceania's people".

One common way to analyze the characteristics of a language (variation) is to look at its lexical, syntactic, and discourse features. Orwell's Principles of the New Speech focuses on the lexical features of the new speech (Orwell, 1949:590-603), the latter two of which we may get some hints from the five sentences in the text, which are included in the appendix.

In terms of vocabulary, if we follow the classification given by Orwell himself, newspeak could be divided into three categories, except for imaginary words, of which category A (simple verbs and nouns necessary for everyday life) and category $C$ (scientific and technical vocabulary) are inherited from standard English. Category B is a special political vocabulary, mainly compound words which are made from two or more words or roots; although such man-made compound words are not easy to comprehend at first glance, they are easy to understand when effort could be put with the one or two words that form them. Many words and expressions, especially those with political meaning(s), have been removed from Newspeak's vocabulary directly so that newspeak words have few usable expressions. This feature determines the character of the "single meaning" of its words, which would not be easy, causing ambiguity problems. The vast majority of the standard English inflexions have been eliminated or de-specialized — by "de-specialization", it would mean that all the special forms of the inflections have been eliminated and replaced by some neat and standardized form, or be cancelled fully. For example, the only morphological changes in verbs are "-ed" (past tense and past participle), "-ing" (the present participle), and "-s" (third-person singular). When the word is to be changed to an adjective, the suffix "-ful" is added uniformly, "-wise" is added for adverbs, and "-er" is added for nouns. In addition, the comparative and 
highest grades like "more" and "most" have been eliminated and replaced by the neat and tidy "-er" and "-est". In short, almost all meanings are expressed through the form of "basic words + simple unifying affixes".

In terms of syntax, the author provides the reader with five sentences in Nineteen Eighty-Four, four written by literati who majored in standard newspeak, and another one written in a non-standard "lingua franca" style by O'Brien, a member of the "Inner Party" and head of the "Thinkpol" (Orwell, 1949:329+461). These sentences have several characteristics: first, a newspeak sentence visually appears to use a much lower number of words than its standard English version and have a simpler sentence structure. Second, standard newspeak sentence(s) has no punctuation and no case; the one written by O'Brien retains punctuation in the form of English words and also has a case. From this, it can be inferred that the basic features of newspeak sentences are that they require fewer words than standard English to describe the same content, and that the sentences they form are simpler, and that the days of using sentence structure and composition to hide deeper meanings will be gone because of the reduction in the number of words and the simplification of meaning, together with the simplification of the structure of the sentences themselves.

Theoretically (or it may be said "textually"), Theoretically, newspeak as English's novel variation is officially encouraged by the "Oceania" officials and seems to have its own advantage of "simplicity", so it might not be difficult for newspeak to quickly replace standard English as the nation's new official language. However, according to Nineteen Eighty-Four, the "Ocean State" came to power in the early 1950s after a civil war, but the new variation just did not fully implement in more than thirty years; not only was the majority of the country's written and spoken materials still in standard English, but even the elite at the top of the regime like O'brien could not fully master the new variation. The official date for the full implementation of the new language is "2050", more than half a century later, which seems to be inconsistent with the characteristics of the new language that we have intuitively summarized so far.

\subsection{The Concept of Language Simplification Movement}

The Chinese name of movements of similar type is described as "整顿文风运动(Movement to Fix People's Style of Using Words)". Such movements had occurred both in ancient (for example, Tang Dynasty and Song Dynasty) and modern times, with the unchanged aim of changing the style of the literary world, which was flamboyant and difficult to pronounce and to promote the use of simple and plain language which is "rich and vivid" (Xu, 2016; Yang, 2021). In addition to literary style, the later part of Qing Dynasty also saw the rise of the "文字简化运动 [simplification of characters movement]", and the famous "Latinization of Chinese characters" was a scheme to simplify Chinese characters. However, the actual implementation of the Chinese character simplification program did not take place until the year 1956 (Ye et al., 2006).

The simplification movement in the English-speaking world also began around the end of the 19th century and the beginning of the 20th century, with the aim of changing the ornate and pompous style of writing to a more practical and concise style of writing, one of the most famous movements being the "Plain English" movement.

\subsection{The Concept of Plain English}

In the late 1960s and early 1970s, a series of linguistic movements to simplify the style and use of words swept through Englishspeaking countries such as the United States, Britain, and Australia, and their significant impact has continued to this day: the "Plain English" movement. In fact, in the late 1960s and early 1970s, "Plain English" was already relatively mature, and it is generally believed that the prototype of this movement had already appeared in the early 20th century. Chinese scholar Li Changshuan analyzed the linguistic characteristics of "Plain English" from the perspectives of vocabulary, syntax and discourse, and considered that this linguistic movement is more suitable for non-literary fields (Li, 2012). In recent years, some scholars have combined "Plain English" with literary criticism, arguing that the American prototype of "Plain English" emerged as early as the 17th century with the birth of early American literature, and it is certainly applicable to the field of literary studies (Liang \& Guo, 2020).

\section{Is Newspeak a Simplification of Standard English?}

If a language is gradually evolving toward being concise and economical, there must be corresponding signs. From the point of view of the characteristics of the word itself, it is intuitive that the language variation should be more concise and that the language will reflect streamlined features in vocabulary, syntax, and text structure(s). For example, the use of complex ancient and academic vocabulary is reduced, the simplest possible syntax is used, and a variety of discourse articulations and transitions are used to help text users more easily find and understand the key information in the text (sentence). In terms of the actual use of the text, the language variation will likely replace the original language style or even part of the text itself in a short period, considering that it is more concise and easier to understand than its prototype and that it may also be encouraged and implemented by the policy. This section is a comparative study based on these ideas, using the newspeak and one of the representatives of the language simplification movement, the Plain English Movement. 


\subsection{Aspects of Wording, Syntax and Text Structures}

In terms of vocabulary, "Plain English" is based on the vocabulary accumulated in the development of Standard English, and uses fewer words that are introduced from difficult sources such as Latin, and uses native words and simple borrowing words as much as possible. At the same time, "Plain English" emphasizes humanism in its diction and takes full care of women and cultural taboos. For example, when "sailor" is acceptable, "seaman", which can be used synonymously under certain circumstances, will not be used. The fact that "Plain English" does not use certain words does not mean that it necessarily rejects or eliminates them; in fact, it emphasizes a kind of "exclusive use of words", without using the words to show their own literary skills or to make things difficult for the readers by making them difficult to understand. However, newspeak divides users of it into three categories by dividing its vocabulary into the same types, and a large number of words and expressions have been directly deleted to make the vocabulary and expressions used "simpler". Most of the difficult words were "eliminated", and the remaining words and expressions were naturally relatively "simple". As for the C category vocabulary, since it inherits the technical vocabulary of Standard English without any reservation, the usage will not be changed greatly, and it is mainly used by the scientific and technical practitioners in Oceanic countries. Some of the words created in the new language are mainly found in the B category vocabulary, which is mainly compound words, and a word may have more than one affix and may use a complex word as the root of the word. For example, "Ministry of Peace" is written as "Minipax" in the newspeak form, which appears to use two fewer words than "Ministry of Peace" in standard English, but a closer look at the composition of "Minipax" reveals that it consists of the root word "pax" (Latin word for "peace") and the prefix "Mini-". In addition to the fact that "pax" itself is rarely used because of its difficulty, the use of the prefix "mini-" is also confusing: in the text ", mini-" is used to denote a government department The prefix "mini-" is used to indicate a government department and can be understood as "ministry". But "mini-" also means "small". If the reader approaches "Minipax" directly without being exposed to the principle of "INSOC" in the preceding paragraph, he or she is likely to be ambiguous when confronted with this term.

In terms of syntax, "Plain English" emphasizes "average length," "simple structure," and "highlighting important information. "The limited average sentence length limits the amount of information and the number of messages in a sentence so that the reader is not overwhelmed by a long sentence and cannot grasp the main point. The sentence structure is not deliberately sculpted to violate the flow of information. At the same time, punctuation and other means are used to highlight the key information at the beginning or end of the sentence, supplemented by concise vocabulary to help the reader quickly locate and understand the sentence's meaning. From the sentences disclosed in Nineteen Eighty-Four(Orwell, 1949:334), the standard newspeak sentence is "minimal", which can express two sentences consisting of thirty-four standard English words in one sentence of ten words, and these two sentences more or less meet the standard of concise English. However, the sentence is not appropriately divided into meaning groups, and no case is given. In the year 1984 in Nineteen Eighty-Four, even well-read members of the Inner Party must use punctuation and case(Orwell, 1949:461) to issue executive orders in a comprehensible manner, even though the punctuation is presented in the form of words.

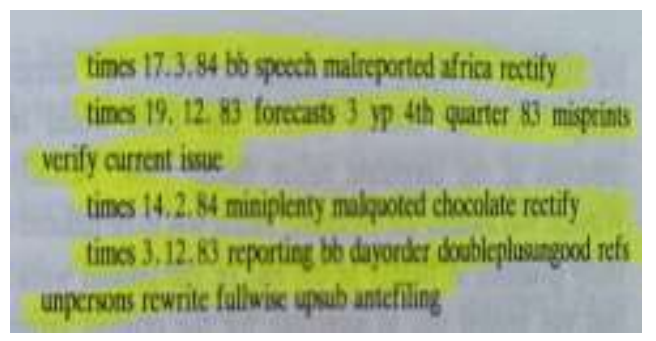

Figure $1:$ Standard newspeak sentences, no case or meaningful punctuation could be found.

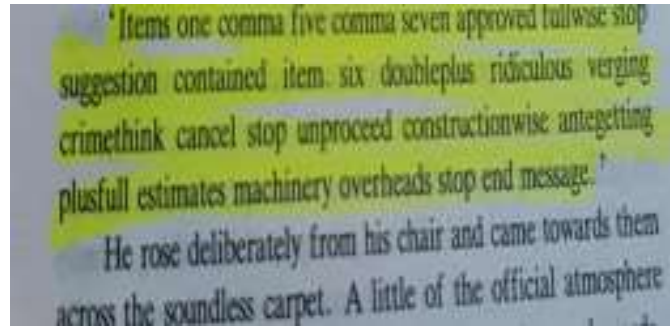

Figure 2 : Newspeak order written by O'brien, punctuation and case could be clearly found.

Although no long passage written in newspeak is included in Nineteen Eighty-Four, considering that standard newspeak does not have explicit punctuation or case breaks, it is reasonable to speculate that newspeak is probably also without any punctuation; this certainly makes it more difficult for readers to understand than standard English.

\subsection{Language Variations' Implementation Situations}

"Plain English" is in line with the basic laws of language development, and probably had its initial germination in Europe as early as the modern era, and embarked on the "fast track" of development after the large-scale language and script simplification activities that took place in English-speaking countries in the 1960s and 1970s. At present, it is still popular in English-speaking countries as a respected style of writing, education and teaching, and is one of the important signs of the "high and profound" academic institutions and government agencies that are kind and friendly to the people. 
Although newspeak is a linguistic variation that only exists in fictional works, and it is certainly impossible to find similar arguments in real life, this does not prevent us from making a general inference about the use of newspeak in light of the textual evidence: the average person cannot master newspeak without a high level of education, and the main force that can master neologisms (the best educated "peripheral party" and "core party") The main force (members of the "peripheral party" and the "core party" with the best education) that could master the new language combined was only fifteen percent of the total population of Oceania(Orwell, 1949:499). In terms of the effectiveness of use, only five new sentences appear in the body of Nineteen EightyFour (excluding the appendix), all in written form and all in official documents circulating within the government. In terms of form, even the top brass of the Inner Party, like O'brien, could not standardize the use of newspeak, which could only be written by professionals working with words and might not be used until "the year 2050" _— this is the best indicator of a language(variation) 's difficulty.

\section{Why does it Exist?}

Based on the lexical and textual (sentence) characteristics of the newspeak, the user of such language variation and the difficulty of the language variation, newspeak can be seen as a variation of the language that at first glance does seem to have a certain degree of simplicity, but in essence, is not _ although it achieves a certain degree of formal "economy" but is essentially a complex and incomprehensible "freak". Why did Orwell create such a monstrosity of "appearance"? There may be several reasons; some are listed below according to the author:

\subsection{Vigilance against totalitarianism}

Stalin's outstanding contribution to world peace by leading the Soviet people to win the Second World War cannot be denied. But at the same time, it is also hard to deny the viciousness of Stalin's centralization of power, as he was willing to kill his comrades to gather all the power for himself(Ma, 2012). During the "Great Purge [Большаячистка]", a large number of talented people who could have shone in the construction of Soviet socialism were murdered because Stalin considered them a "threat" (to himself), and for these people, Stalin's image was similar to that of a "traitor". Trotsky was undoubtedly one of the most important of the persecuted: not only was he wanted by the government, but all his writings, speeches, images and images in the country were wiped out, and he could only accept the scorn of the people without being able to defend himself — this is very similar to the "traitor massacre" in Animal Farm and the criticism of "Goldstein" in Nineteen Eighty-Four (Song, 2015). Stalin's all-encompassing critique of Trotsky, which left him with no chance to fight back, echoes the rationale for the creation of a B category word in newspeak: the development of a language (system) that can help one's own public opinion to "spit out" language "as quickly as a machine gun fires bullets "arguments without giving the opponent any chance to respond.

At the same time, left-wing thinking in the West rapidly gained momentum after the war. But these left-wing parties seemed to be very powerful, but they did not form a fist. After the collapse of the Soviet Union, a large number of such small parties disbanded, while some simply changed sides and "defected" — until now, the general character of the world's development is "rising in the east and falling in the west", but it still shows a "shift to the left". Until now, although the general character of the world development is "rising in the east and falling in the west", it still shows a pattern of "strong capitalism and weak socialism, and the two sides will have long-term competition" (Feng \& Wang, 2021). Orwell was very interested in fighting for freedom and democracy, but his own experience in the Spanish Civil War made him aware of the difficulty of winning; therefore, he created a series of works such as Animal Farm and Nineteen Eighty-Four, which warned readers by creating images such as "newspeak" and called on everyone to be alert to the infiltration of totalitarianism from all sides, including language.

\subsection{Orwell's View of Language as a Propagating Weapon}

Orwell knew the power of language, and by creating such a "freak" (newspeak) in Nineteen Eighty-Four, he hoped that people would pay more attention to the traditional language and words and would not easily lose their weapons of broadcasting their voices because of the emergence of new media. The ultimate goal of the newspeak was to replace Standard English, making "thoughtcrime impossible," which means no politically dangerous words could be spoken or written, and no conscientious opponents of totalitarianism could make their voices heard. This still has a rich relevance in today's proliferation of "短视频(Duan Shipin, which means fast-food cultural vehicles such as short videos)", "音频读书(Yinpin Dushu, indicating buying service of listening to professional readers reading books instead of literally reading a paper-book)" and "提笔忘字(Tibi Wangzi, which stands for forgetting how to spell some words, because we are too dependent on computer-typing)" (Dujmovic, 2011).

\section{Conclusion: Terrifying, but not inevitable}

Based on the study's findings, we can conclude that although newspeak has some textual features of "simplicity", it is rather complicating the standard English rather than simplifying it. Only very few people in Oceania who have the highest education level could master such a language in the novel. Newspeak as a cumbersome and redundant variation of English may ultimately 
eliminate all dissenting voices. It is not only a fictional linguistic variation but also a profound cultural image designed to warn readers of the invasion of totalitarianism and to call on fighters of freedom and democracy to value and defend man's autonomy of language and words from being taken away by totalitarians.

Newspeak is a horrendous "weapon of words" that, upon closer examination, makes one feel anxious, but Orwell leaves us with a glimmer of hope among the darkness and gloom he created throughout his Nineteen Eighty-Four: the newspeak, because of its own complexity as well as redundancy, does not conform to the economy feature of the language, and this variation, even if it were to appear in reality, would still be temporarily outgunned against standard language. We still have time before the last breath of fresh air would be polluted with smog.

However, as Orwell only provided very few sentences and paragraphs of Newspeak, only by studying these few words, sentences and texts might not fully reveal what Orwell wished to demonstrate to readers. So for researchers, it would be desirable next step to combine the features of Newspeak with the plot of the book and of the real world and other relevant theories. For example, Michel Foucault's theories on the relationship between discourse and power.

Funding: This research received no external funding.

Conflicts of Interest: The authors declare no conflict of interest.

\section{References}

[1] Вахитов, Р. Р. \& Vakhitov, R (2021). Правильно ли мы понимаем "1984"? [Do We Understand "1984" Correctly?].Мир России. Социология. Этнология [Universe of Russia. Sociology. Ethnology].(30): 151-162.

[2] Bi S. Z, (2015). The Way to Salute: Analysis of the Inner Connectivity between Nineteen Eighty-Four and 1Q84. Research on Sinoforeign Literary \& Arts Theories (2014-2015), (00): 443-448.

[3] Cao J. H. (2018). The Comparative Study Between Murakamiharuki's 1Q84 and Orwell's Nineteen Eighty-Four. Hebei University, MA dissertation.

[4] Dujmovic, M, (2011). Turbulent New World. DRUSTVENA ISTRAZIVANJA, (20): 541-560.

[5] Feng YL, Wang SC, (2021). Development Patterns, Main Features and Path to Prosperity of World Socialism Today.Journal of Southwest University (Social Sciences Edition).47(01):31-41+225.

[6] Gan CY, Wang XD (2004). On the Economy Characters of Discourse Implemented in Business English. Journal of Southwest Minzu University (Humanities and Social Science)., (10): 330-332.

[7] Guo K, (2002). The International Spread and Influence of English as a Dominating Language. Modern Communication (Journal of the Communication University of China)., (06): 26-29.

[8] Karel, T, (2019). The Ministry of Truth: The George Orwell's 1984. Library Journal. (05):97.

[9] Li C.S (2012). Theory and Practice on Non-Literary Translation. Beijing: China Translation \& Publishing House.

[10] Liang LQ \& Guo GQ, (2020). Exploring the Prototype Version of "Plain English" in the Early Period of American Literature. In the Proceedings of the ICLAHD 2020 Conference.

[11] Lonrenzo F.C (2018). UNESCO 1984: between Kafka and Orwell, the keys to the withdrawal of the United States. Historia Y Communication Social. (23):273-274.

[12] Ma LS. (2012). Why Stalin Started the Great Purge. Yanghuang Chunqiu [History of the Chinese People]. (08):60-63+71.

[13] Nie SM. (2016). Criticism on Orwell in an ethical context. Journal of Gansu Radio \& Television University., 26(05):26-29.

[14] Orwell G. (1949). Nineteen Eighty-Four. Translated by Dong Leshan. Shanghai: Shanghai Translation Publishing House: 278, 329+461, 461 , 499, 334, 590-603.

[15] Peng P, (2015). うートピアと個人:現代体制の下に自由を求める可能性一一村上春樹「1Q84」とオーウエル「1984」の対照研究[Utopia and Individuals: Possibility of Pursuing Liberty Under Modern Social Mechanism], Soochow University, MA dissertation.

[16] Rodden J, (2020). The Orwellian "Amerika" of Donald J. Trump?. Society. (57):260-264.

[17] Song YH, (2015). The Political Irony of Napoleon's Image in Animal Farm. Journal of Hulunbeier University, 23(06): 62-65.

[18] Xu L, (2016) The analysis of Hanyu's practical writing. Changchun University of Science and Technology, MA dissertation.

[19] Yang JJ, (2021). Reconstruction of the Revolutionary Nature of Modern Chinese Literature by the "Discourse of Workers, Peasants and Soldiers". Journal of Xiamen University(Arts \& Social Sciences). (01): 151-158. 